\title{
Pemphigus vulgaris: A review
}

\author{
Sanchita Kant ${ }^{1 *}$, Mayuri Jaitley ${ }^{2}$, Swati Kant ${ }^{3}$, Manoj Samant ${ }^{4}$ \\ ${ }^{1}$ Consultant, ${ }^{2}$ Senior Lecturer, ${ }^{3,4}$ Consultant, Dept. of Oral Medicine \& Radiology, Sri Aurobindo College of Dentistry, \\ Indore, Madhya Pradesh, India
}

*Corresponding Author: Sanchita Kant

Email: sanchitakant@gmail.com

\begin{abstract}
Pemphigus is an autoimmune inter epidermal blistering disorder. it is characterized by mucosal and cutaneous vesicles, bullae, erosions. It has an array of maifesations and symptoms. Systemic corticosteroids have remained the mainstay of treatment for pemphigus, recent years are focusing on use of other immunomodulators as well. This review looks at the etiology, clinical features, management, complications of the condition.
\end{abstract}

Keywords: Pemphix, Rheumatoid arthritis, Myasthenia gravis.

\section{Introduction}

The word pemphigus is as old as the medicine, with first description in literature by Hippocrates (460-370 BC) as "pemphigoides pyertoi" to describe fever associated with blisters. The term 'Pemphigus', derived from the Greek word "pemphix" meaning bubble or blister. ${ }^{1}$ It refers to a group of life threatening autoimmune intraepidermal bullous diseases of the skin and mucous membranes with antibodies directed against keratinocytes, thereby causing loss of adhesion or acantholysis. The incidence of pemphigus in India is relatively common, earliest reported literature in India is dated back to 1960 by Desai and Rao who described 21cases of pemphigus. ${ }^{2}$ Pemphigus is classified based on histological \& clinical features, major categories being pemphigus vulgaris, pemphigus foliaceus, paraneoplastic pemphigus, IgA pemphigus, drug induced pemphigus and recently identified variants being pemphigus herpetiformis and $\mathrm{IgG} / \mathrm{IgA}$ pemphigus. ${ }^{3}$ However, only pemphigus vulgaris (PV) and paraneoplastic pemphigus (PNP) typically have oral involvement, this contribution focuses on pemphigus vulgaris being the protypical form of this disease.

\section{Epidemiology}

Incidence of pemphigus worldwide has been reported to be 1 to 16 per million people per year ${ }^{4}$ with $70 \%$ cases reported from South East Asia, Middle East Asia \& China. ${ }^{5}$ Pemphigus Vulgaris being the most common variant mean incidence being 0.1 to 0.5 per 100,000 with incidence in India being 75 and $92 \%$ of all cases of pemphigus. ${ }^{6,2}$ The mean age of occurrence being 50 and 60 years in European countries and between the ages of 30 and 50 in rest of world. ${ }^{7}$ In India the age of patients being less than 40 years of age constitute approximately $50 \%$ patients. ${ }^{2,8}$ A higher incidence in female population has been reported with Male: Female ratio being 1:1.1-2.25. ${ }^{9}$ however few studies in India have reported a higher incidence in males with Male: Female ratio being 3: 1, 3: $2 .^{8}$

\section{Aetiology}

A strong genetic background has been linked with pemphigus vulgaris owing to higher incidence in certain ethnic groups (Mediterranean and South Asian population and Ashkenazi Jews). There are also associations with HLA, particularly with HLA-DR4 (DRB1*0402) in Ashkenazi Jews and, in Europeans and Asians, with DRw14 (DRB1*1041) and DQB1*0503.; ${ }^{10-14}$ early age of onset in Indian population has been related to occurrence of DRB1*1404，DQA1*0101，DQB1*0503 allele. ${ }^{2,8}$ Recently ST18, a gene regulating apoptosis and inflammation, has been suggested in predisposing individuals to pemphigus vulgaris in Jeweish and Russian population. ${ }^{15}$ Most cases the precipitating factor is usually unknown and pemphigus is considered to be idiopathic ostensibly certain trigger agents such as diet, drugs, contact allergens, stress or viruses have been identified. ${ }^{1,16}$

\section{Pathogenesis}

In pemphigus vulgaris, IgG autoantibodies are targeted against desmogleins, the cell adhesion molecules of the desmosome, leading to loss of cell to cell adhesion resulting in acantholysis. Desmoglein-1 (Dsg-1) is expressed in all layers of the epidermis with a higher concentration in the subcorneal layer and desmoglein3 (Dsg-3) expressed in the parabasal and basal layers. The mucosa expresses both Dsg-1 and Dsg-3 however, the mucosa has lower concentrations of Dsg-1. ${ }^{12}$ In 
mucocutaneous pemphigus vulgaris autoantibodies are directed against Dsg-1 and Dsg-3 whereas in only mucosal disease antibodies are exclusively against Dsg-3.

\section{Pemphigus autoantigen}

With advances in diagnostic pathology target antigens have been recognized in pemphigus. The reported "pemphigus antigens" include over 40 protein bands with apparent molecular weights (MWs) of 12, 18, 25, $30,33,35,38,40,45,47,50,52,55,57,59,60,62$, $66,67,68,70,75,78,80,85,95,100,102,105,110$, $112,120,130,140,160,170,180,185 / 190,210$, and $260 \mathrm{kD}$. Various self-antigens recognised by pemphigus IgG include adhesion molecules, cell membrane receptors, annexins, immunologic/hematologic antigens, neuronal/oncologic antigens and thyrogastric cluster antigens ${ }^{19}$

It is known that antibodies play an important role in pathogenesis of pemphigus however the exact pathogenesis of these antibodies is not known. Various theories have been proposed for the pathogenesis of pemphigus including the desmoglian compensation theory, the multiple hit hypothesis, antibody induced apoptic theory, steric hinderance and basal cell shrinkage hypothesis. ${ }^{20-23}$

\section{Clinical features}

Oral mucosa is typically involved, $80 \%$ patients have oral lesion as first sign of pemphigus vulgaris ${ }^{6,24-25}$ and $50 \%$ of patients with pemphigus vulgaris have isolated oral lesions. Oral lesion of pemphigus in children are rarely seen. ${ }^{26-27}$ Most commonly involved site being buccal mucosa, palate, ventral surface of tongue, labial mucosa and gingiva. Lesions occur as flaccid vesicles \& bullae of oral cavity associated with ulcers, desquamative gingivitis or dysphagia. ${ }^{16,17}$ Gingival lesions appear later in disease, presenting as isolated blisters or erosions of marginal gingiva and attached gingiva in advanced cases. ${ }^{29-31}$ Nikolsky's sign is a common examination finding. The direct Nikolsky sign refers to direct application of pressure on a blister, causing the extension of the blister. The indirect Nikolsky sign is when the application of friction on clinically normal skin induces a blister. ${ }^{32}$ Any mucosal surface, including conjunctiva, nasal mucosa, larynx, oropharynx, esophagus, urethra, vulva, and cervix may be involved. ${ }^{33-40}$ Painful but rarely pruritic flaccid bullae and erosions of body accompany oral manifestations involving face, trunk, axilla and groin. ${ }^{40,41}$ Other clinical findings include nail dystrophy, paronychia, and subungual hematomas.
Nail involvement in pemphigus was first documented by Sinclair and colleagues in 1998, has been reported to be present in $34.2 \%$ patients and can precede skin findings. They can manifest as paronychia, onychomadesis /Beau line or onycholysis and nail involvment has been associated with poor prognosis. ${ }^{42-}$ ${ }^{44}$ Scalp is frequently involved in pemphigus, hair involvement in pemphigus may differentiate it with other vesiculobullous disorders. It is associated with anagen effluvium with and without alopecia ${ }^{22}$ and is considered as Nikolsky's sign of the scalp and can be used to verify disease activity. It has been propose d that the scalp is the first site of clinical manifestation of disease. ${ }^{45-47}$

\section{Association with other disorders}

PV may occasionally be associated with other autoimmune disorders, particularly rheumatoid arthritis, myasthenia gravis, thyroid disorders, lupus erythematosus, vitiligo or pernicious anaemia. ${ }^{48-50}$

\section{Diagnosis}

Clinical examination and diagnostic modalities aid in the diagnosis of pemphigus. Direct and indirect immunofluorescence, enzyme linked immunosorbent assays (ELISA) and immunoblot are helpful in distinguishing the different subtypes of pemphigus. Light microscopy is an important modality in the diagnosis of the pemphigus demonstrating typical suprabasal cleft in epithelium of pemphigus vulgaris patients. Demonstrates intercellular deposition of $\mathrm{IgG}$, $\operatorname{IgA}, \operatorname{IgM}$ and $\mathrm{C} 3$. The immune deposits precede clinical appearance hence it is considered more sensitive than histopathology. DIF of plucked hair can be a useful test in the diagnosis of pemphigus, sensitivity ranging from 85 to $100 \%$. Also can be used to assess disease activity with accuracy of $73.3 \% .^{51}$ Indirect immunofluorescence demonstrates serum autoantibodies against desmosomal antigens causes staining of IgG antibodies in typical "Fishnet pattern" or "Chicken wire appearance" positive predictive value of $90 \%$ in active pemphigus vulgaris patients and sensitivity of $75 \%$ with specificity of $83 \% .^{52-53}$ ELISA can demonstrate IgG antibodies to Dsg1 and Dsg3. Advantage being its simplicity and highly sensitive approach to confirm the initial diagnosis of PV with overall accuracy for diagnosis of PV $93.7 \%$ and sensitivity of $92-100 \% .{ }^{54}$ Immunoblot is recently developed technique which can differentiate between PV and PF or clinical phenotypes of PV demonstrating antibodies against $130 \mathrm{kda}$ and $160 \mathrm{kda}$ in mucocutaneos type, for mucosal type at $130 \mathrm{kda}$ and in 
pure cutaneous type $160 \mathrm{kda}$. Diagnostic accuracy of $95.7 \%$ and sensitivity of $95.7 \%$ has been reported. ${ }^{54}$

\section{Comorbidities}

Complications of pemphigus include sepsis, malnutrition and dehydration. However, with advent of corticosteroid in management of pemphigus mortality from pemphigus vulgaris has reduced from $90 \%$ to present rate of $5-6 \% .^{55,56}$ The side effects of immunosuppressive agents being the most common cause of morbidity and mortality. Dental complications owing to inadequate oral hygiene maintenance with active lesions due to pain and / or hemorrhage leading development and / or progression of periodontal disease. ${ }^{57,58}$

\section{Remission rate}

A high remission rate has been described in US being $94.6 \%$ with drug free remission in $25 \%, 50 \%$ and $75 \%$ of patients after 2, 5 and 10 years. In Korea remission rate has been reported to be $77 \%$ at 5 years and $94 \%$ at 10 years. In India, there is only one such study available which reported remission of $34.6 \%$ in patients on dexamethasone-cyclophosphamide pulse cycle at the duration of 3.33 years. ${ }^{59}$

\section{Management}

Various treatment modalities for management of pemphigus available are

1. Topical therapy

2. Systemic therapy

3. Pulse therapy

4. Plasmapheresis

European dermatology forum in 2014 has suggested guidelines for management of pemphigus. The workup recommended before initiation of systemic therapy includes complete blood count, creatinine and blood electrolytes levels, transaminases, alkaline phosphatase, total serum protein, albumin levels, fasting serum glucose and chest X-ray also infection like T. B., Hepatitis B, C and HIV should be ruled out. Recommended investigations indicated based on therapeutic used in management, including serum IgA levels to rule out IgA deficiency prior to IVIG treatment; also thiopurine methyltransferase (TPMT) activity should be determined when azathioprine is being used; Quantiferone or PPD is recommended in case of elevated risk for TB; G6PD serum activity, bilirubin, reticulocyte count if dapsone planned; pregnancy should be excluded; prior to corticosteroid treatment osteodensitometry and ocular examination for glaucoma or cataract is recommended. ${ }^{60}$

\section{Topical therapy}

Topical agents is indicated for mild oral lesions. Topical anaesthetic rinses, provide temporary relief and high-potency topical corticosteroids in forms of rinses, pastes, gels used as monotherapy or in conjunction. Topical tacrolimus is beneficial for recalcitrant lesions. Intralesional corticosteroid injections for isolated lesion, but has been associated with scarring and / or mucosal atrophy. ${ }^{9,60}$

\section{Systemic corticosteroids}

First-line systemic treatment for moderate to severe pemphigus. An effective initial dose of corticosteroids has been suggested to be $1 \mathrm{mg} / \mathrm{kg} / \mathrm{d}^{56,61}$ however there is no universal consensus regarding the same. Initial oral prednisolone dose of $40-60 \mathrm{mg} / \mathrm{d}$ has been recommended by some author whereas others have reported an initial dose up to $120 \mathrm{mg} /$ day to be more effective. ${ }^{61}$ However, Benjamin S Daniel;(2015), have concluded though higher doses $(120 \mathrm{mg} /$ day) result in a more rapid control of disease than lower doses $(60$ $\mathrm{mg}$ /day), there is no evidence that the higher doses are beneficial in the long term. The corticosteroids are tapered to $2.5 \mathrm{mg}$ per month. ${ }^{62}$

Managing pemphigus usually requires a prolonged corticosteroids course ( $>3$ months), the preventive measures for glucocorticoid-induced osteoporosis must be considered including oral bisphosphonates, along with 800 international units of vitamin D and $1200 \mathrm{mg}$ calcium. Bisphosphonates are indicated in postmenopausal women, elderly males with a high fracture risk, on a dose of prednisone $>7.5 \mathrm{mg}$ daily for three months. ${ }^{63}$ Also symptoms of adrenal insufficiency, hypertension, diabetes mellitus, infections, gastrointestinal ulcers, steroid myopathy, and mood instability should be looked for.

\section{Immunomodulators in management of pemphigus}

Numerous studies have reported and recommended use of immunomodulators as adjuvant to systemic steroids to minimise the side effects of corticosteroids use. Immunosuppressant popularly used in past were gold, dapsone and methotrexate however they were associated with severe side effects especially at higher dose. Ongoing studies have opened new horizons for therapeutic options in managing pemphigus mycophenolate mofetil, azathioprine and intravenous cyclophosphamide pulse therapy are being the most popular choices for adjuvant therapy.

\section{Azathioprine}

A Purine synthesis inhibitor promotes inhibition of DNA synthesis in proliferating $\mathrm{B}$ and $\mathrm{T}$ cells has 
shown a superior steroid-sparing effect when compared to other adjuvant therapies. The recommended dose being $1-3 \mathrm{mg} / \mathrm{kg}$ daily. The combined prednisolone and azathioprine protocol proved to be the most effective in terms of disease mortality and remission ${ }^{41}$ Cochrane review suggests that glucocorticoids dosage can be decreased when combined with azathioprine or cyclophosphamide. ${ }^{64}$

\section{Mycophenolate mofetil:}

Has been indicated as combination therapy and monotherapy in dosage of 1-3 g/day. It has shown improved time to and duration of response also studies have shown it to be more effective in disease control than azathioprine. ${ }^{42}$ Decrease time required for healing. The Cochrane review, Beissert et al.;(2010) have demonstrated in a randomized clinical trial that, in comparison to corticosteroids used as monotherapy, the addition of mycophenolate mofetil may be advantageous, since it achieved a faster and longer lasting response than corticosteroids alone. ${ }^{65}$ A study of 18 patients attempted to determine a standard treatment regimen based on a retrospective chart review. Complete disease control was achieved in $89 \%$ patients. In 14 of these patients, complete control was reached with mycophenolate mofetil at 1 gram BID and prednisone at $1 \mathrm{mg} / \mathrm{kg}$ daily. Prednisone was held steady, mycophenolate mofetil was increased by 0.5 grams every month, until a maximum dose of 3 grams daily was reached. The other 2 patients required further treatment with rituximab. ${ }^{66}$ Daniell B et al.; 2014, have reported similarities in efficacy and side effect profiles, azathioprine or MMF as first-line therapy hence no study has been able to prove one to be more effective than the other. ${ }^{67}$ Sinha AA; (2015), have reported that mycophenolate mofetil has been shown to have a rapid effect in lowering pemphigus antibody titers and disease activity and has fewer side effects than azathioprine.

However, mycophenolate mofetil was inferior to azathioprine and cyclophosphamide in regards to steroid-sparing effect. ${ }^{46}$

\section{Cyclophosphamide}

Alkylating agent that selectively inhibits lymphopoietic cells while sparing hematopoietic cells and inhibits antibody-producing B cells. Has shown faster onset and more sustained remission. The recommended dose being Dose: $2-2.5 \mathrm{mg} / \mathrm{kg}$ daily. ${ }^{47}$ Benjamin S. Daniel; 2014 reported RCT by ChamsDavatchi C, which showed similar efficacy with azathioprine, mycophenolate mofetil (MMF), and intravenous cyclophosphamide. The steroid-sparing effect was demonstrated only when all three agents were pooled together as one group. ${ }^{67}$

\section{Cyclosporine}

Several randomized controlled trials have failed to demonstrate a beneficial effect of oral cyclosporine either alone or as adjuvant therapy. One study compared cyclosporine plus steroids, cyclophosphamide plus steroids and steroids alone. Remission and relapse rates were similar in all three groups, and there was no clear benefit of using a combination. ${ }^{68-70}$

\section{Methotrexate}

Immunosuppressive agent that decreases autoimmune disease pathogenesis. Decreases disease activity and remission time recommended in dose of $15 \mathrm{mg} / \mathrm{week}$ or $1 \mathrm{mg}$ daily. ${ }^{48,49}$

\section{Dapsone}

As an adjunctive recommended dose being 100-300 mg daily. However several studies have concluded the effect of dapsone on remission and withdrawal to be inconclusive. ${ }^{71-74}$

\section{Intravenous immunoglobulin}

IVIG selectively removes the pathogenic antibodies without affecting the level of "normal" antibodies. IVIG also alters the expression and function of $\mathrm{Fc}$ receptors, affects activation, differentiation and effector functions of $\mathrm{T}$ cells and $\mathrm{B}$ cells and works to decrease the response to autoantibodies by interfering with the complement pathway and cytokine activation. ${ }^{75}$ Single cycle of high dose IVIG of $2 \mathrm{~g} / \mathrm{kg}$ divided into 2 or 3 equal doses, given on 3 consecutive days, repeated every 4 weeks. A multicenter RCT by Amagai et al; compared various doses of IVIg found patients treated with a higher dose of IVIg had a better outcome Patients received one of three doses of 0 $\mathrm{mg} / \mathrm{kg}$ per day, $200 \mathrm{mg} / \mathrm{kg}$ per day and $400 \mathrm{mg} / \mathrm{kg}$ per day. There was a dose-response relationship with more patients benefiting from the higher dose and objectively. $^{76}$

\section{Rituximab}

Antibodies against CD20, a protein expressed by most developing and memory $\mathrm{B}$ cells has been considered as the most promising agent for complete or partial remission however relapses are common and is indicated mainly for patients with PV refractory to at least two therapeutic modalities. ${ }^{77}$ It has also been used as a first-line treatment with favourable outcomes. Two dosing schedules have been suggested 
the lymphoma protocol of weekly IV infusions of 375 $\mathrm{mg} / \mathrm{m} 2$ once weekly for 4 weeks and a rheumatoid arthritis protocol of two $1 \mathrm{~g}$ infusions, administered 2 weeks apart. High-dose $(\geq 2,000 \mathrm{mg})$ Rituximab was associated with longer complete remission compared with low-dose Rituximab $(<1,500 \mathrm{mg})$. In report by Cianchini et al; 200711 patients with refractory PV, patients received a combination of high-dose IVIG and 2 cycles of rituximab once weekly for 3 weeks followed by 4 consolidation rituximab infusions monthly for 4 months This regimen resulted in a sustained complete remission in $82 \%$ of patients after only 7-9 weeks, lasting an average of 31.1 months. A larger study consisting of 21 patients found that $86 \%$ of patients (18 out of 21) with severe pemphigus on prednisone achieved complete remission at 3 months after receiving single cycles of rituximab once weekly for 4 weeks. ${ }^{78}$ Current evidence supports the efficacy of RTX in treating patients with pemphigus, with $76 \%$ remission. Although the long-term efficacy of many of the therapies in pemphigus has not been evaluated Colliou N, (2013) have reported it to be $60 \%$ of patients with severe pemphigus treated with rituximab were in long-term remission of 6 years. $^{79}$ In comparison, the remission rates for patients managed in the Ratnam;5-year study were $36 \%$ with a dose of $120 \mathrm{mg} / \mathrm{kg}$ per day and $9 \%$ with a starting dose of 60 $\mathrm{mg} / \mathrm{kg}$ per day. ${ }^{53}$ Meta analysis by Wang et al.;2015, supports the efficacy of Rituximab in treating patients with pemphigus, with $76 \%$ of patients achieving complete remission. Mean remission duration was 14.5 months, with an overall relapse rate of $40 \%{ }^{78}$

\section{Dexamethasone cyclophosphamide pulse (DCP) regimen}

First developed by Pasricha and Ramji in 1982 for treatment of psoriasis patients. It has been extensively used in India owing to its low cost of therapy and considerably less side effects of pulsed steroids. It consisits of four phases. Phase I: DCP therapy given in the presence of signs and symptoms. Patients receive monthly doses of $100 \mathrm{mg}$ of dexamethasone dissolved in $500 \mathrm{~mL}$ of $5 \%$ dextrose by slow intravenous infusion over 2 hour on three consecutive days along with $500 \mathrm{mg}$ of cyclophosphamide in the infusion on day 2. In between, the patients received $50 \mathrm{mg}$ of oral cyclophosphamide daily. Phase II: Patients were in remission but monthly DCP therapy and daily oral cyclophosphamide were continued for 9 months. Phase III: Only oral cyclophosphamide $50 \mathrm{mg}$ is given to patients for an additional 9 months. Phase IV: All treatments are withdrawn and patients. ${ }^{80,81}$
Parmar N V et al.; (2013) found no difference in the clinical outcome between patients receiving nine DCPs in phase II and patients shifted directly from phase I to III. ${ }^{82}$ A randomized control trial of 20 patients showed that pulsed oral dexamethasone $(300$ $\mathrm{mg} / \mathrm{d}$ for 3 days) in addition to oral prednisolone and azathioprine does not improve time to remission, duration of remission or mortality. This study concluded that prednisolone, $80 \mathrm{mg} /$ day on a tapering schedule to $0 \mathrm{mg}$ in 19 weeks with azathioprine sodium, $3 \mathrm{mg} / \mathrm{kg}$ continued for a year after tapering, is the most effective regimen for patients with new disease activity. ${ }^{83}$

Meta analysis by Atzmony et al.;2015 Remission was reported in 6 trials including 378 patients treated with Oral glucocorticoids and MMF $(n=112)$, Azathioprine $(\mathrm{n}=58)$, Cyclophosphamide $(\mathrm{n}=40)$, Cyclosporine $(n=24)$, Oral glucocorticoides alone ( $n$ $=144$ ). The addition of adjuvants was not associated with an increase in remission patients.

Disease control was reported in 8 trials including 190 patients treated with azathioprine $(\mathrm{n}=28)$, MMF $(\mathrm{n}=24)$, cyclophosphamide $(\mathrm{n}=44)$, IVIG $(\mathrm{n}=41)$, cyclosporine $(n=24)$, plasma exchange $(n=19)$, or infliximab $(\mathrm{n}=10)$ compared with 149 patients treated with oral GCs alone. The addition of adjuvants was not associated with acheiving disease control. Relapse was reported in 7 trials including 338 patients treated with MMF ( $\mathrm{n}=92)$, Cyclophosphamide $(\mathrm{n}=57)$, Azathioprine $(\mathrm{n}=39)$, Cyclosporine $(\mathrm{n}=24)$, Compared with 126 patients treated with oral GCs alone. The addition of adjuvants resulted in a significantly lower Relapse in patients.Specifically MMF, azathioprine, and cyclophosphamide were shown to decrease relapses.

A study concluded that prednisolone, $80 \mathrm{mg} /$ day on a tapering schedule to $0 \mathrm{mg}$ in 19 weeks with azathioprine sodium, $3 \mathrm{mg} / \mathrm{kg}$ continued for a year after tapering, is the most effective regimen for patients with new disease activity. ${ }^{84}$

European guideline for autoimmune bullous disease; 2014 has recommended first line therapeutics for management of pemphigus Azathioprine in Dose: $1-3 \mathrm{mg} / \mathrm{kg} /$ day to be started on first week $50 \mathrm{mg} /$ day and raised to desired dose or mycophenolate mofetil at Dose of 2g/day or Mycophenolic acid (1440 mg/day) Raise daily dose by 1 capsule per week. The second line adjuvant being Rituximab 2 x $1 \mathrm{~g}$ i.v. (2 weeks apart) $4 \times 375 \mathrm{mg} / \mathrm{m} 2$ (each 1 week apart) or intravenous immunoglobulins at dose of $2 \mathrm{~g} / \mathrm{kg} /$ month or Immunoadsorption at 2 cycles à 4 days, 4 weeks apart. Cyclophosphamide at dose of $500 \mathrm{mg}$ as i.v. bolus or Orally as $2 \mathrm{mg} / \mathrm{kg} / \mathrm{day}$. Methotrexate at 10-20 
$\mathrm{mg} /$ week or Dapsone Dose: $100 \mathrm{mg}$ /day or up to $\leq 1.5$ $\mathrm{mg} / \mathrm{kg} / \mathrm{day}$

\section{Conclusions}

Systemic corticosteroids are the mainstay of treatment for pemphigus. Much of the recent research has been assessing the efficacy of steroid-sparing agents, most commonly azathioprine, MMF, Rituximab, methotrexate, IVIg, and cyclophosphamide. Although strong evidence in the form of RCTs is lacking, because of the rarity of the disease, studies are often underpowered and fail to demonstrate a statistically significant difference between the active and control groups. The evidence to date indicates that adding an adjuvant to steroids has a significant steroid-sparing effect, reducing the cumulative exposure to steroids. Azathioprine and MMF are often considered first-line therapies for PV with good improvement. Rituximab is beneficial in patients who have poorly controlled disease despite high-dose steroids or steroid-sparing agents (or both) or are contra-indicated for receiving steroids. IVIg in short-term studies is effective for recalcitrant cases but its duration of treatment needs further investigation and further research with larger RCTs is required.

\section{Source of funding}

None.

\section{Conflict of interest}

None.

\section{Reference}

1. Ruocco V, Ruocco E, Schiavo AL, Brunetti G, Guerrera LP, Wolf R, et al. Pemphigus: Etiology, pathogenesis, and inducing or triggering factors: Facts and controversies. Clin Dermatol 2013;31:374-81.

2. Amrinder J. Kanwar, Dipankar De.Pemphigus in India. Indian J Dermatol, Venerol, Leprol 2011;77:439-49.

3. Vasconcelos PLde, Caetano N, Sena Ld, Maehara N, Santos Enokihara MMdos. Non-classical forms of pemphigus: pemphigus herpetiformis, IgA pemphigus, paraneoplastic pemphigus and $\mathrm{IgG} / \mathrm{IgA}$ pemphigus. $A n$ Bras Dermatol 2014;89(1):96-117.

4. Zhou T, Zhou P, Hua H, and Liu X. Beneficial Effects and Safety of Corticosteroids Combined with Traditional Chinese Medicine for Pemphigus: A Systematic Review. Hindawi Publishing Corporation Evidence-Based Complementary and Alternative Medicine Volume 2015

5. Venugopal SS, Murrell DF. Diagnosis and clinical features of pemphigus vulgaris. Dermatol Clin 2011;29:373-80:vii

6. World Workshop on Oral Medicine VI: A systematic review of the treatment of mucocutaneous pemphigus vulgaris R. McMillan. Triple O 2015;1-11.

7. Alpsoy E, Akman-Karakas A, Uzun S. Geographic variations in epidemiology of two autoimmune bullous diseases: pemphigus and bullous pemphigoid. Arch
Dermatol Res 2015;307(4):291-8. doi: 10.1007/s00403014-1531-1. Epub 2015 Jan 15.

8. Kanwar AJ, Vinay K. Treatment of pemphigus: An Indian perspective. Indian J Dermatol Venereol Leprol 2014

9. Frank A. Santoro, Eric T. Stoopler, D.M.D., and Victoria P. Werth, Pemphigus. Dent Clin North Am. 2013;57.

10. Lombardi ML, Mercuro O, Tecame G, Molecular analysis of HLA DRB1 and DQB1 in Italian patients with pemphigus vulgaris. Tissue Antigens 1996;47:228-30.

11. Mobini N, Padilla Jr T, Ahmed AR. Long-term remission in selected patients with pemphigus vulgaris treated with cyclosporine. J Am Acad Dermatol 1997;36:264-6.

12. Delgado JC, Hameed A, Yunis JJ. Pemphigus vulgaris autoantibody response is linked to HLA-DQB $1 * 0503$ in Pakistani patients. Hum Immunol 1997;57:110-9.

13. Loiseau P, Lecleach L, Prost C. HLA class II polymorphism contributes to specify desmoglein derived peptides in pemphigus vulgaris and pemphigus foliaceus. $J$ Autoimmun 2000;15:67-73.

14. Crispian Scully a,*, Michele Mignognab. Oral mucosal disease: Pemphigus. Br J Oral Maxillofac Surg 2008;46:272-7.

15. Sarig O, Bercovici S, Zoller L, Goldberg I, Indelman M, Nahum $S$ et al, Population-specific association between a polymorphic variant in ST18, encoding a pro-apoptotic molecule, and pemphigus vulgaris. J Invest Dermatol 2012;132(7)

16. Tur E, Brenner S. Diet and pemphigus. In pursuit of exogenous factors in pemphigus and fogo selvagem. Arch Dermatol 1998;134:1406-10.

17. Amagai M, Tsunoda K, Zillikens D. The clinical phenotype of pemphigus is defined by the anti-desmoglein autoantibody profile. J Am Acad Dermatol 1999;40:16770. [PubMed: 10025740]

18. 10. Shirakata Y, Amagai M, Hanakawa Y. Lack of mucosal involvement in pemphigus foliaceus may be due to low expression of desmoglein 1. J Invest Dermatol 1998;110:76-8. [PubMed: 9424092]

19. Sergei A. Grando Pemphigus autoimmunity: hypotheses and realities. Autoimmunity. Taylor Francis $J$ 2012;45(1):7-35

20. Mahoney MG, Wang Z, Rothenberger K, Koch PJ, Amagai M, Stanley JR et al. Explanations for the clinical and microscopic localization of lesions in Pemphigus foliaceus and vulgaris. J Clin Invest 1999;103:461-8.

21. Grando SA. Autoimmunity to keratinocyte acetylcholine receptors in Pemphigus. Dermatol 2000;201:290-5.

22. Amagai M. Autoimmunity against desmosomal cadherins in Pemphigus. J Dermatol Sci 1999;20:92-102.

23. Udey MC, Stanley JR. Pemphigus - diseases of antidesmosomal autoimmunity. J Am Med Assoc 1999;282:572 - 576.

24. Sirois DA, Fatahzadeh M, Roth R, Ettlin D. Diagnostic patterns and delays in pemphigus vulgaris: experience with 99 patients. Arch Dermatol 2000;136:1569-70.

25. Kneisel A, Hertl M. Autoimmune bullous skin diseases. Part 1: clinical manifestations. J Dtsch Dermatol Ges 2011;9:844-856: quiz 857.

26. Mignogna MD, Fortuna G, Leuci S. Oral pemphigus. Minerva Stomatol 2009;58(10):501-18

27. Pisanti S, Sharav Y, Kaufman E, Posner LN. Pemphigus vulgaris: incidence in Jews of different ethnic groups, according to age, sex, and initial lesion. Oral Surg Oral Med Oral Pathol 1974;38:382-7. 
28. Mignogna MD, Pannone G, Lo Muzio L, Staibano S, Bucci E. Catenin dislocation in oral pemphigus vulgaris. J Oral Pathol Med 2001;30:268-74.

29. Murer M, Millns JL, Rogers RS III, Jordon RE. Oral pemphigus vulgaris. A report of ten cases. Arch Dermatol 1977;113:1520-4.

30. Shklar G, Frim S, Flynn E. Gingival lesions of pemphigus. J Periodontol 1978;49:428-35.

31. Sirois DA, Fatahzadeh M, Roth R, Ettlin D. Diagnostic patterns and delays in pemphigus vulgaris: experience with 99 patients. Arch Dermatol 2000;136:1569-70.

32. Seshadri D, Kumaran MS, Kanwar AJ. Acantholysis revisited: Back to basics. Indian J Dermatol Venereol Leprol 2013;79:120-6.

33. Mignogna MD, Lo Muzio L, Galloro G, Satriano RA, Ruocco V, Bucci E et al. Oral pemphigus: clinical significance of esophageal involvement: report of eight cases. Oral Surg Oral Med Oral Pathol Oral Radiol Endod 1997;84:179-84.

34. Hodak E, Kremer I, David M. Conjunctival involvement in pemphigus vulgaris: a clinical, histopathological and immunofluorescence study. Br J Dermatol 1990;123:61520.

35. Hale EK, Bystryn JC. Laryngeal and nasal involvement in pemphigus vulgaris. J Am Acad Dermatol 2001;44:609-11.

36. Lurie R, Trattner A, David M. Esophageal involvement in pemphigus vulgaris: report of two cases and review of the literature. Dermatol 1990;181: 233-6.

37. Trattner A, Lurie R, Leiser A. Esophageal involvement in pemphigus vulgaris: a clinical, histologic, and immunopathologic study. J Am Acad Dermatol 1991;24:223-6.

38. Marren P, Wojnarowska F, Venning V, et al. Vulvar involvement in autoimmune bullous diseases. $J$ Reprod Med 1993;38:101-7.

39. Sagher F, Bercovici B, Romem R. Nikolsky sign on cervix uteri in pemphigus. Br J Dermatol 1974;90:407-11.

40. Korman N. Pemphigus. J Am Acad Dermatol 1988;18:1219-38.

41. Uzun S, Durdu M. The specificity and sensitivity of Nikolsky sign in the diagnosis of pemphigus. J Am Acad Dermatol 2006;54:411-5.

42. Berker DD, Dalziel K, Dawber RP. Pemphigus associated with nail dystrophy. Br J Dermatol 1993;129:461-4.

43. Kolivras A, Gheeraert $P$, Andre J. Nail destruction in pemphigus vulgaris. Dermatol 2003;206:351-2.

44. Tosti A, André M, Murrell DF, FAAD, FACDc Nail Involvement in Autoimmune Bullous Disorders. Dermat Clin 2011;29(3):511-3, xi

45. Veraitch O, Ohyama M, Yamagami J, Amagai M. Alopecia as a rare but distinct manifestation of pemphigus vulgaris. $J$ Eur Acad Dermatol Venereol 2013;7(1):86-91.

46. Hadayer N, Ramot Y, Maly A, and Zlotogorski A. Pemphigus Vulgaris with Loss of Hair on the Scalp. Int J Trichol 2013;5(3):157-8.

47. Sar-Pomian M, Kurzeja M, Rudnicka L, Olszewska M. The value of trichoscopy in the differential diagnosis of scalp lesions in pemphigus vulgaris and pemphigus foliaceus. An Bras Dermatol 2014;89(6).

48. Coda AB, Qafalijaj Hysa V, Seiffert-Sinha K. Peripheral blood gene expression in alopecia areata reveals molecular pathways distinguishing heritability, disease and severity. Genes Immun 2010;11:531-41.
49. Subramanya RD, Coda AB, Sinha AA. Transcriptional profiling in alopecia areata defines immune and cell cycle control related genes within disease-specific signatures. Genomics 2010;96:146-53.

50. Sinha AA, The Genetics of Pemphigus. Dermatol Clin 2011;29:381-91

51. Raghavendra Rao, Kavitha Dasari,1 Shrutakirthi D Shenoi, C Balachandran, and P Dinesh. Monitoring the Disease Activity in Pemphigus by Direct Immunofluorescence of Plucked Hair: A Pilot Study. Indian J Dermatol 2013;58(2):164

52. Helou J, Allbritton J, Anhalt G. Accuracy of indirect immunofluorescence testing in the diagnosis of paraneoplastic pemphigus. J Am Acad Dermatol 1995;32:441-7. [PubMed: 7868713]

53. Mutasim DF, Adams BB. Immunofluorescence in dermatology. J Am Acad Dermatol 2001; 45:803-22. [PubMed: 11712024]

54. Khandpur S, Sharma VK, Sharma A, Pathria G, Satyam A. Comparison of enzyme-linked immunosorbent assay test with immunoblot assay in the diagnosis of pemphigus in Indian patients. Indian J Dermatol Venereol Leprol [serial online] 2010:76:27-32. Available from: http://www.ijdvl.com/text.asp?2010/76/1/27/58675

55. Scully C, Mignogna M. Oral mucosal disease: pemphigus. Br J Oral Maxillofac Surg 2008;46:272-7.

56. Sinha AA, Hoffman MB, Janicke EC. Pemphigus vulgaris: approach to treatment. Eur J Dermatol 2015; 25(2):103-13 doi:10.1684/ejd.2014.2483

57. Akman A, Kacaroglu H, Yilmaz E. Periodontal status in patients with pemphigus vulgaris. Oral Dis 2008;14:640-3. [PubMed: 18627505]

58. Thorat MS, Raju A, Pradeep AR. Pemphigus vulgaris: effects on periodontal health. J Oral Sci 2010;52:449-54. [PubMed: 20881339]

59. Ajithkumar K. Long-term prognosis of pemphigus in central Kerala, India: A retrospective cohort study. Indian J Dermatol Venereol Leprol 2014;80:64-5.

60. Lagha B N, Poulesquen V, Roujeau JC. Pemphigus vulgaris: A case-based study. J Can Dent Assoc 2005;71:667-72. [PubMed: 16271165]

61. Pemphigus. S2 Guideline for diagnosis and treatment Guideline on the Diagnosis and Treatment of Autoimmune Bullous Diseases - Pemphigus. J Eur Acad Dermatol Venereol 2014;29(3):405-14.

62. Daniel BS. and Murrell DF. Management of pemphigus F1000Prime Medicine Reports. F Prime Rep Med 2014;6.

63. Canalis E, Mazziotti G, Giustina A. Glucocorticoidinduced osteoporosis: pathophysiology and therapy. Osteoporos Int 2007;18:1319-28. [PubMed: 17566815]

64. Martin LK, Agero AL, Werth V, Villanueva E, Segall J, Murrell DF. Interventions for pemphigus vulgaris and pemphigus foliaceus. Cochrane Database Syst Rev 2009. doi: 10.1002/14651858. CD006263.

65. Beissert S, Mimouni D, Kanwar AJ, et al. Treating pemphigus vulgaris with prednisone and mycophenolate mofetil: a multicenter, randomized, placebo-controlled trial. J Invest Dermatol 2010; 130: 2041-8.

66. Strowd LC, Taylor SL, Jorizzo JL, Namazi MR. Therapeutic ladder for pemphigus vulgaris: emphasis on achieving complete remission. J Am Acad Dermatol 2011; 64: 490-4.

67. Chams-Davatchi C, Esmaili N, Daneshpazhooh M, Valikhani M, Balighi K, Hallaji Z et al, Randomized 
controlled open-label trial of four treatment regimens for pemphigus vulgaris. J Am Acad Dermatol 2007;57:622-8.

68. Chrysomallis F, Ioannides D, Teknetzis A, Panagiotidou D, Minas A: Treatment of oral pemphigus vulgaris. Int J Dermatol 1994:33:803-7.

69. Sharma VK, Khandpur S: Evaluation of cyclophosphamide pulse therapy as an adjuvant to oral corticosteroid in the management of pemphigus vulgaris. Clin Exp Dermatol 2013:38:659-64.

70. Rose E, Wever S, Zilliken D, Linse R, Haustein UF, Brocker EB et al: Intravenous dexamethasonecyclophosphamide pulse therapy in comparison with oral methylprednisolone-azathioprine therapy in patients with pemphigus: results of a multicenter prospectively randomized study. J Dtsch Dermatol Ges 2005;3:200-6.

71. Yeh S, Sami N, Ahmed R. Treatment of pemphigus vulgaris: current and emerging options. Am J Clin Dermatol 2005;6:327-42.

72. Beissert S, Mimouni D, Kanwar AJ. Treating pemphigus vulgaris with prednisone and mycophenolate mofetil: a multicenter, randomized, placebo-controlled trial. J Invest Dermatol 2010;130:2041-8.

73. Chams-Davatchi C, Esmaili N, Daneshpazhooh N, et al. RcoltoftrfpvJAAD-. Randomized controlled open-label trial of four treatment regimens for pemphigus vulgaris. $J$ Am Acad Dermatol 2007; 57: 622- 8.

74. Strowd LC, Taylor SL, Jorizzo JL, Namazi MR. Therapeutic ladder for pemphigus vulgaris: emphasis on achieving complete remission. J Am Acad Dermatol 2011;64:490-4.

75. Kazatchkine MD, Kaveri SV. Immunomodulation of autoimmune and inflammatory diseases with intravenous immune globulin. N Engl J Med 2001;345:747-55.

76. Amagai M, Ikeda S, Shimuzu H, Iizuka H, Hanada K, Aiba $\mathrm{S}$ et al. A randomized double blind trial of intravenous immunoglobulin for pemphigus. J Am Acad Dermatol 2009; 60: 595-603.

77. Lunardon L, Tsai KJ, Propert KJ. Adjuvant rituximab therapy of pemphigus: a single center experience with 31 patients. Arch Dermatol 2012;148:1031-6. [PubMed: 22710375]

78. Hsiao-Han WANG, Che-Wei LIU, Yu-Chuan LI and YuChen HUANG. Efficacy of Rituximab for Pemphigus: A Systematic Review and Meta-analysis of Different Regimens. Acta Derm Venereol 2015 Epub ahead of print

79. Colliou N, Picard D, Caillot F, Calbo S, Le Corre S, Lim A et al, et al. Long-term remissions of severe pemphigus after rituximab therapy are associated with prolonged failure of desmoglein B cell response. Sci Transl Med 2013, 5:175130 .

80. Pasricha JS. Pulse therapy in pemphigus and other diseases. 3rd ed. Pulse Therapy and Pemphigus Foundation. New Delhi; 2006.

81. Pasricha JS, Gupta R. Pulse therapy with dexamethasonecyclophosphamide in pemphigus. Indian $J$ Dermatol Venereol Leprol 1984;50:199-203.

82. Parmar NV, Kanwar AJ, Minz RW, Parsad D, Vinay K, Tsuruta D, et al. Assessment of the therapeutic benefi t of dexamethasone cyclophosphamide pulse versus only oral cyclophosphamide in phase II of the dexamethasone cyclophosphamide pulse therapy: A preliminary prospective randomized controlled study. Indian J Dermatol Venereol Leprol 2013;79:70-6.

83. Mentink L, Mackenzie M, Toth G. Randomized controlled trial of adjuvant oral dexamethasone pulse therapy in pemphigus vulgaris: PEMPULS trial. Arch Dermatol 2006;142:570-6.

84. Lihi A, Emmilia H, Yael LA. Omer R, Michael G, Grant A $\mathrm{J}$ et al, Published undefined $\mathrm{NaN}, \mathrm{NaN}$. () The role of adjuvant therapy in pemphigus: A systematic review and meta-analysis Article in Press: Corrected Proof. J Am Acad Dermatol. 2015.

How to cite: Kant S, Jaitley M, Kant S, Samant M. Pemphigus vulgaris: A review. Int Dent J Student Res 2020;8(1):1-8. 